\title{
Blood meal origins and insecticide susceptibility of Anopheles arabiensis from Chano in South-West Ethiopia
}

Fekadu Massebo ${ }^{1,3^{*}}$, Meshesha Balkew ${ }^{2}$, Teshome Gebre-Michael ${ }^{2}$ and Bernt Lindtjørn ${ }^{3}$

\begin{abstract}
Background: Anopheles arabiensis, the main malaria vector in Ethiopia, shows both anthropophilic and zoophilic behaviours. Insecticide resistance is increasing, and alternative methods of vector control are needed. The objectives of this study were to determine the blood meal origins and the susceptibility to insecticides of An. arabiensis from Chano village near Arba Minch in South-West Ethiopia.

Methods: Blood meal sources of anopheline mosquitoes collected using Centers for Disease Control and Prevention (CDC) light traps and pyrethrum spray catches (PSC) from human dwellings, and hand-held mouth aspirators from outdoor pit shelters were analysed using a direct enzyme-linked-immunosorbent assay (ELISA). The susceptibility of An. arabiensis to pyrethroid insecticides (alphacypermethrin, lambdacyhalothrin, deltamethrin, and cyfluthrin) and DDT was assessed using females reared from larval and pupal collections from natural breeding sites.
\end{abstract}

Results: The blood meal origins of 2967 freshly fed Anopheles mosquitoes were determined. An. arabiensis was the predominant species (75\%), and it fed mainly on cattle. The densities of both freshly fed An. arabiensis and those fed on human blood followed similar seasonal patterns. The overall human blood index (HBI) of An. arabiensis, including mixed blood meals, was $44 \%$ and the bovine blood index (BBI) was 69\%. The HBI of An. arabiensis from CDC light trap collections was 75\% and this was higher than those for PSC (38\%) and outdoor pit shelter collections (13\%), while the BBI was $65 \%$ for PSC, $68 \%$ for outdoor pit shelters and $72 \%$ for CDC light traps. More freshly fed and human blood-fed An. arabiensis were sampled from houses close to the shore of Lake Abaya (the major breeding site).

A high proportion of An. arabiensis was resistant to the pyrethroid insecticides, with a mortality rate of $56 \%$ for lambdacyhalothrin, 50\% for cyfluthrin and alphacypermethrin, 47\% for deltamethrin, and 10\% for DDT.

Conclusion: Anopheles arabiensis is the predominant species of anopheline mosquito in this region, and cattle are the main source of its blood meals. The greater tendency of this species to feed on cattle justifies the application of insecticides on cattle to control it. However, An. arabiensis has already developed resistance to the available pyrethroid insecticides, and alternative insecticides are needed for malaria vector control.

Keywords: Anopheles arabiensis, Human blood index, Bovine blood index, Pyrethroid insecticides, DDT, Insecticide resistance, South-West Ethiopia

\footnotetext{
* Correspondence: fekimesi@yahoo.com

${ }^{1}$ Department of Biology, Arba Minch University, Arba Minch, Ethiopia

${ }^{3}$ Centre for International Health, University of Bergen, Bergen, Norway

Full list of author information is available at the end of the article
} 


\section{Background}

Malaria vectors that feed mainly on humans seriously affect human health because this behaviour increases the risk of malaria transmission [1]. The feeding pattern of $A n$. arabiensis, the main vector of malaria in Ethiopia, varies among households [2]; it shows both zoophilic [3] and anthropophilic behaviours [4,5]. In Ethiopia, only a few studies have examined the blood meal origins of $A n$. Arabiensis, particularly focusing on mosquitoes from animal sheds and human dwellings in the main malaria transmission seasons $[3,5,6]$. Such studies might have underestimated or overestimated the human-vector contact and the risk of malaria transmission [7].

Pyrethroid insecticides are widely used for bed net treatment, and for indoor residual spraying (IRS) [8] to reduce malaria incidence $[9,10]$. Long lasting insecticide treated nets (LLINs) and IRS have contributed to a reduction of malaria incidence in many malaria endemic countries by reducing the number of mosquitoes inside houses $[11,12]$. IRS and LLINs are efficient malaria vector control measures for An. gambiae s.s, which mostly feeds and rests indoors [13,14]. In contrast, $A n$. arabiensis obtains a large proportion of its blood meals from cattle, apart from humans, and exhibits significant exophilic behaviour $[4,6,13]$. Thus, treatment of cattle with insecticide may reduce $A n$. arabiensis populations in an alternative approach to malaria vector control $[15,16]$. In southern Ethiopia, Habtewold et al. [3] observed normal feeding behaviour of An. arabiensis on insecticide treated cattle with no diversion to humans. Moreover, Rowland et al. [15] reported a 56\% reduction in the incidence of malaria in Pakistan resulting from the application of deltamethrin insecticide to cattle. In Africa, deltamethrin treated cattle provided protection against $A n$. arabiensis in experimental huts [16].

Resistance to deltamethrin and permethrin in $A n$. arabiensis has been reported from different parts of the country $[17,18]$. DDT resistant $A n$. arabiensis is widespread in the country, including Arba Minch [17-19]. There has not been any information regarding susceptibility/resistance of $A n$. arabiensis to pyrethroids from the area. Therefore, it is important to examine the insecticide susceptibility and blood meal origins of $A n$. arabiensis from Chano in South-West Ethiopia for planning alternative or additional vector control approach.

\section{Methods}

\section{Study area}

The study was conducted in Chano, a village $15 \mathrm{~km}$ north of Arba Minch town in South-West Ethiopia, from May 2009 to April 2010. The village is located at $6^{\circ} 6.666 / \mathrm{N}$ and $37^{\circ} 35.775^{\prime} \mathrm{E}$ and at altitude of $1,206 \mathrm{~m}$ above sea level. There are three sub-villages, named subvillages 1, 2 and 3 . The village is close to Lake Abaya and sub-village 3 is found at a distance of 1350 to $1850 \mathrm{~m}$ from the lake. Three major irrigation canals pass through the village. The canals are permanent, wellconstructed and flow into the agricultural fields outside the village. The inhabitants are subsistence farmers with maize cultivation and cattle ranching as their main source of income. The main cash crops are mangoes and bananas.

Domestic animals are usually kept in compounds in open conditions, but a few households use separate roofed cow shelters. It is not customary to keep animals in human dwellings. The people habitually sleep indoors throughout the year. There is no permanent or seasonal movement of animals out of the village for feeding or watering. The human population size is 6661 while the cattle population is 2217 (approximately three humans per head of cattle) (Table 1).

The climate is hot and humid. Potential mosquito breeding sites are located at the shores of Lake Abaya and Harrae River. Small water bodies created by hoofprints of cattle and hippopotami are the major breeding sites for Anopheles mosquitoes. Harrae River is a potential location for the breeding of anopheline mosquitoes during the dry seasons when many small water pouches are available. However, its influence is much smaller than that of Lake Abaya because it is about $5 \mathrm{~km}$ from the village. Monthly rainfall was recorded from the weather station in Arba Minch University, about $6 \mathrm{~km}$ from the study area, which is located at an altitude of $1200 \mathrm{~m}$ above sea level (the same as Chano village). In 2009, the annual rainfall was $645 \mathrm{~mm}$, and in 2010 it was $1061 \mathrm{~mm}$. The average minimum and maximum annual temperatures in 2009 were 17.8 and $32.2^{\circ} \mathrm{C}$, and in 2010 they were 17.9 and $30.2^{\circ} \mathrm{C}$.

\section{Study components and vector control activities in the area}

This study is a part of the research programme "Ethiopian Malaria Prediction System," which researches malaria and climate. The village was purposely selected, because it is one of the malarious villages in the Arba Minch area, for study of the epidemiological and entomological components of the disease and for the development of

Table 1 Abundance of human and other potential blood meal hosts in the three sub-villages from Chano in Southwest Ethiopia

\begin{tabular}{ccccccc}
\hline & \multicolumn{5}{c}{ Human and other potential hosts } \\
\cline { 2 - 7 } Sub - villages & Human & Cattle & Goat & Sheep & Donkey & Chicken \\
\hline 01 & 2289 & 568 & 90 & 112 & 36 & 261 \\
02 & 2154 & 696 & 80 & 161 & 31 & 373 \\
03 & 2218 & 953 & 83 & 166 & 42 & 557 \\
Total & 6661 & 2217 & 253 & 439 & 109 & 1191 \\
\hline
\end{tabular}


mathematical models to predict malaria. A recent publication by Loha and Lindtjørn described the occurrence of falciparum malaria in the village [20]. Antivector interventions, such as the application of IRS with DDT and distribution of insecticide treated nets (ITNs), were carried out by the government in June 2009 and March 2010, respectively. At least two bed nets were provided for each household.

\section{Mosquito collections}

Mosquito sampling was conducted biweekly for a total of 12 consecutive months (May 2009 to April 2010) after obtaining verbal consent from the heads of households. Indoor blood-searching Anopheles were collected from ten randomly selected houses using Centers for Disease Control and Prevention (CDC) light traps (New Standard Miniature Light Traps 5126 V 150A; John W. Hock, Gainesville, FL) by positioning the traps $45 \mathrm{~cm}$ above the floor at the feet of sleeping persons, who were protected by mosquito nets untreated with insecticide, from 18:30 to 6:00 hours [21]. Indoor resting mosquitoes were sampled in the mornings (6:00 to 9:00) from ten other randomly selected houses by application of the pyrethrum spray catch (PSC) method. Prior to spraying with an aerosol (Roach killer, M/S Kafr EI Zayat, Egypt with Registration No. ET/HHP/130) in each house, all food items and small animals were removed, the openings and eaves of windows and doors were filled with pieces of cloth, and the floor and furniture were covered with white sheets. Two sprayers, one from outside and the other inside the house were engaged, and knocked down mosquitoes were collected after ten minutes [22]. Outdoor resting mosquitoes were collected using a handheld mouth aspirator, paper cup and torch from ten pit shelters constructed under the shade of mango trees in the compound of ten randomly selected houses. Each shelter was $1.5 \mathrm{~m}$ deep and had an opening of $1.2 \mathrm{~m} \times 1.2 \mathrm{~m}$. About $0.5 \mathrm{~m}$ from the bottom of each pit shelter, a $30 \mathrm{~cm}$ horizontally deep cavity was prepared for each of the four sides [23]. The mouth of each pit shelter was covered with untreated bed net during collection periods (6:30-10:00 hours) to prevent mosquitoes from escaping.

\section{Mosquito processing}

Live female anopheline mosquitoes were killed by freezing and all females were identified to species level using morphological characteristics [24]. Female anopheline mosquitoes were examined under a dissecting microscope and classified on the basis of their abdominal condition as unfed, freshly fed, half-gravid and gravid [22]. All female mosquitoes were preserved individually in vials with silica gel desiccant for later analysis (blood meal origins, parity rate and sporozoite rate).

\section{Detection of blood meal sources}

The blood meal origins of freshly fed anopheline mosquitoes collected outside and inside houses were determined using a direct enzyme-linked immunosorbent assay (ELISA) following the method of Beier et al. [25] using human and bovine antibodies. Each mosquito abdomen was crushed in $50 \mu \mathrm{l}$ phosphate buffered saline (PBS) solution ( $\mathrm{pH}$ 7.4), which was further diluted by adding $950 \mu \mathrm{l}$ PBS. Fifty microlitres of sample was added to each well in a 96-well microtitre plate, and incubated overnight at room temperature. Each well was washed twice with PBS containing Tween-20 solution, and $50 \mu \mathrm{l}$ host specific conjugate (either human or bovine) was added to each well and incubated for one hour. After one hour, each well was washed three times with a PBS-Tween-20 solution. Finally, $100 \mu \mathrm{l}$ of peroxidase substrate was added to each well and after 30 minutes the absorbance at $405 \mathrm{~nm}$ was recorded with an ELISA plate reader. Each blood meal sample was considered positive if the absorbance value exceeded the mean plus three times the standard deviation of the four negative controls (from a laboratory colony of An. arabiensis adults not fed with blood). Positive controls contained human and bovine blood.

\section{Species identification}

Species specific polymerase chain reaction (PCR) [26] was carried out on 300 morphologically identified individuals from the An. gambiae complex obtained by random sampling for each month.

\section{Collection of aquatic forms and rearing to adulthood for susceptibility tests}

Anopheles larvae and pupae were collected from natural breeding sites on the shores of Lake Abaya and along the Harrae River. They were reared to adulthood in the entomology laboratory at Arba Minch University in cages and provided with sterilized 10\% sucrose solution soaked in cotton pads until testing. Before the test, Anopheles mosquitoes were identified using morphological keys [24] and those identified as from the An. gambiae complex (presumably An. arabiensis) were used for the test.

\section{Insecticide susceptibility tests}

Insecticide susceptibility tests were carried out following the standard World Health Organization (WHO) protocol, using insecticide susceptibility test kits and insecticideimpregnated papers [27]. For each replicate, twenty nonblood-fed female An. Arabiensis, three to four days old, were exposed to papers impregnated with cyfluthrin $(0.15 \%)$, lambdacyhalothrin (0.05\%), alphacypermethrin (0.05\%), deltamethrin (0.05\%), and DDT (4\%) for an hour. Controls were exposed to insecticide-free papers. The knockdown effect of each insecticide was recorded every 
five minutes during the one-hour exposure period [27]. Mosquitoes were then transferred to a recovery tube, supplied with sterilized 10\% sucrose solution and kept in an insecticide free box for 24 hours, after which mortality rates were recorded. All susceptibility tests were carried out in a room with temperatures of $26.2-27.4^{\circ} \mathrm{C}$ and relative humidity of $72-84 \%$. Four replicates of the tests and two replicates of the controls were carried out for each insecticide. For each replicate, new insecticide-impregnated paper was used.

\section{Data analysis}

Data were entered and analysed using SPSS version 16 (SPSS Inc., Chicago. IL). The human blood index (HBI) and bovine blood index (BBI) were calculated as the proportion of the mosquitoes fed on either human or bovine blood meals out of the total blood meals determined [7]. Mixed (human + bovine) blood meals were added to the number of human and bovine blood meals when calculating the HBI and BBI $[14,28]$. Cryptic mixed blood meals were not analysed. The chi-squared test was used to compare the HBI and BBI of indoor and outdoor collected An. arabiensis. Analysis of variance (ANOVA) was used to compare the mean differences in the number of freshly fed An. arabiensis among months and sub-villages. The Tukey Honestly Significant Difference (HSD) test was used to distinguish the months with the maximum density of mosquitoes.

The results of the susceptibility tests were evaluated as recommended by WHO [27]. Mean mortality was determined across all batches of mosquitoes for a particular insecticide. Probit analysis was used to calculate $\mathrm{KDT}_{50}$ and $\mathrm{KDT}_{90}$ (the time taken to knock down $50 \%$ and $90 \%$ of mosquitoes, respectively).

\section{Results}

\section{Anopheles species analysed for determination of blood} meal origin

Overall, 3027 anopheline mosquitoes engorged with fresh blood were collected from May 2009 to April 2010, and $98 \%$ ( $n=2967)$ of these were analysed to identify their blood meal origin. Of the $300 \mathrm{An}$. gambiae complex tested for speciation, 99.3\% ( $\mathrm{n}=298)$ were An. arabiensis and two specimens did not amplify using PCR, and hence, their identity was unknown. Therefore, An. arabiensis was regarded as the only member of the complex and the predominant species (75\%), followed by An. marshalli (22\%) and An. garnhami (1.7\%). An. funestus, An. pharoensis and $A n$. tenebrosus accounted for $0.9 \%$.

Seventy nine per cent of all Anopheles species, and $78 \%$ of $A n$. arabiensis, gave positive reactions against human, bovine or both antibodies. Of all Anopheles mosquitoes analysed, $33.5 \%$ were found positive for mixed (human and bovine) blood meals. The host blood meals of $21 \%$ freshly fed Anopheles mosquitoes were not identified, and of these $57 \%(\mathrm{n}=360)$ were from outdoor pit shelters (Table 2).

An. arabiensis was the predominant species in outdoor pit shelters $(64.8 \%)$, in space spray catches $(84.6 \%)$, and in indoor CDC light traps (84.4\%). An. marshalli ( $\mathrm{n}=$ 436, 66.5\%), An. garnhami $(\mathrm{n}=35,71.4 \%)$ and $A n$. funestus group $(\mathrm{n}=14,88 \%)$ were caught more frequently in outdoor pit shelters, whereas $A n$. pharoensis $(\mathrm{n}=7)$ was caught only by indoor CDC light traps.

\section{Feeding behaviour of Anopheles mosquitoes}

Table 2 shows the blood meal origins of Anopheles mosquitoes. An. arabiensis showed an overall preference for bovine bloods (33\%) above human blood meals. Only $8 \%$ of $A n$. arabiensis had obtained a blood meal from humans alone. The proportion of mixed blood meals (human-bovine) was high for An. arabiensis (36\%). A large proportion of $A n$. arabiensis had blood meals of unknown origin (22.5\%). A high proportion of An. arabiensis from CDC light traps (65\%) had blood meals of mixed origin, whereas the lowest proportion of mixed blood meals was obtained from outdoor pit shelters (10\%). Few An. arabiensis from outdoor pit shelters (3\%) had human blood meals alone. Similarly, An. marshalli, An. garnhami, and An. funestus group have shown a preference for bovine blood meals above human blood meals, with bovine blood meals alone in $47 \%, 47 \%$, and $37.5 \%$ respectively. No An. funestus group had a human blood meal alone.

\section{Blood meal indices of An. arabiensis}

Table 3 shows the blood meal origins of An. arabiensis from different collection sites. The overall human blood index (HBI) of $A n$. arabiensis, including mixed blood meals, was $44 \%$, while the bovine blood index (BBI) was $69 \%$. The frequency of human-vector contact was much higher for mosquitoes caught in indoor CDC light traps than for indoor or outdoor resting samples collected by space spraying and from pit shelters. The proportion of human blood meals in $A n$. arabiensis from indoor CDC light traps (75\%) was significantly higher than for outdoor pit shelters $\left(13 \%, \chi^{2}=288.7, p<.0001\right)$ and indoor resting space spray catches $\left(38 \%, \mathrm{X}^{2}=36.6, \mathrm{p}<.0001\right)$. Indoor resting $A n$. arabiensis had a $\mathrm{HBI}$ of $38 \%$ which was significantly higher than the $13 \%$ obtained for samples from outdoor pit shelters $\left(\mathrm{x}^{2}=58.8, \mathrm{p}<.0001\right)$. The proportion of bovine blood meals in An. arabiensis was similar for indoor resting (65\%), outdoor pit shelter resting (68\%) and CDC light trap (72\%) samples.

\section{Household and seasonal variations in density of blood fed An. arabiensis}

The densities of freshly fed An. arabiensis varied significantly among the three sub-villages $(\mathrm{F}=5.0 ; \mathrm{df}=2$; 
Table 2 Sources of blood meal of Anopheles mosquitoes collected indoors and outdoors from Chano in Southwest Ethiopia from May 2009-April 2010

\begin{tabular}{|c|c|c|c|c|c|}
\hline \multirow[t]{2}{*}{ Anopheles spp. } & \multirow[b]{2}{*}{ No. analysed (HBI,\%) } & \multicolumn{4}{|c|}{ Blood meals sources } \\
\hline & & Human N (\%) & Bovine N (\%) & Mixed N (\%) & Unknown N (\%) \\
\hline An. arabiensis & $2234(44)$ & $180(8)$ & 745 (33) & 807 (36) & $502(22.5)$ \\
\hline An. marshalli & $656(37)$ & $68(10)$ & $308(47)$ & $175(27)$ & $105(16)$ \\
\hline An. garnhami & $49(37)$ & $9(18)$ & $23(47)$ & $9(18)$ & $8(16)$ \\
\hline An. funestus group & $16(19)$ & $0(0.0)$ & $6(37.5)$ & $3(19)$ & $7(44)$ \\
\hline An. pharoensis & $7(43)$ & $1(14)$ & $0(0.0)$ & $2(29)$ & $4(57)$ \\
\hline An. tenebrosus & $5(20)$ & $1(20)$ & $1(20)$ & $0(0.0)$ & $3(60)$ \\
\hline Total & $2967(42)^{*}$ & $259(9)$ & $1083(36.5)$ & 996 (33.5) & $629(21)$ \\
\hline
\end{tabular}

Mixed (human + bovine) blood meals were added to the number of human and bovine blood meals when calculating the HBI; numbers in parenthesis. Unknown blood meals are negative for human and bovine antibodies. ${ }^{*}$ Overall HBI of Anopheles mosquitoes.

$\mathrm{p}=0.02$ ). Figure 1 shows the variations in freshly fed and human-blood-fed An. arabiensis among the three sub-villages. The maximum number of freshly fed $A n$. arabiensis was collected in houses in the sub-village nearest to the major breeding site (between $1350 \mathrm{~m}$ and $1850 \mathrm{~m}$ ), with 12.6 per CDC light trap per night, 10.5 per pit shelter and 6 per hut PSC. In contrast, in subvillage 2 (located between $1960 \mathrm{~m}$ and $2270 \mathrm{~m}$ from the major breeding site), the maximum number of freshly fed $A n$. arabiensis was 8.3 per CDC light trap per night, 2.2 per pit shelter per collection time and 0.6 per hut PSC. The maximum number of freshly fed $A n$. arabiensis was 1.5 per CDC light trap per night, 4 per pit shelter and 1.5 per hut PSC in sub-village 1 (located between $2350 \mathrm{~m}$ and $2600 \mathrm{~m}$ from the major breeding site). Similarly, the number of human-blood-fed $A n$. arabiensis was highest in sub-village 3, with 11 fed on human blood per CDC trap per night, 1.8 human fed per hut PSC and 1 human fed per pit shelter.

The density of An. arabiensis varied with season (F = 3.67 ;f $=11 ; \mathrm{p}=0.017$ ) and was associated with rainfall (Figure 2). The density of the total number of freshly fed, human and bovine blood engorged An. arabiensis followed a similar seasonal pattern (Figure 3). The highest number of freshly fed An. arabiensis was collected in April 2010, comprising 24.7 mosquitoes per CDC light trap, 20.8 mosquitoes per pit shelter and 6.9 mosquitoes per hut in space spray catches. In April
2010, we collected the highest number of An. arabiensis with meals of human blood origin from indoor CDC light traps: 16.3 human-blood-fed per CDC light trap per night, 2.5 human-blood fed per pit shelter and 2.4 human-blood fed per PSC. The number of freshly fed An. arabiensis declined to zero in August 2009, following the period of lowest rainfall in the preceding two months. The highest densities of An. arabiensis were collected during October and November 2009, and in April 2010. However, significantly higher densities of freshly fed An. arabiensis were collected in April 2010 than in October and November 2009 (Tukey HSD test, $\mathrm{p}=0.004)$.

\section{Knockdown and mortality of An. arabiensis}

Table 4 shows the knockdown time for the five insecticides used with $A n$. arabiensis. Only deltamethrin resulted in $100 \%$ knockdown, with the lowest $\mathrm{KDT}_{50}$ (21 minutes) and $\mathrm{KDT}_{90}$ (35 minutes) values, whereas DDT resulted in only $10 \%$ knockdown within 60 minutes of exposure time. The $\mathrm{KDT}_{50}$ values of alphacypermethrin, cyfluthrin and deltamethrin were 27, 25 and 21 minutes, respectively. Only cyfluthrin and deltamethrin resulted in more than 90\% knockdown within 60 minutes of exposure time. The $\mathrm{KDT}_{50}$ value of lambdacyhalothrin was 1.9 times, and that of alphacypermethrin was 1.3 times, higher than that of deltamethrin.

Table 3 Blood meal origins of Anopheles arabiensis collected indoors and outdoors from Chano in Southwest Ethiopia

\begin{tabular}{cccccc}
\hline & & \multicolumn{3}{c}{ Blood meal origins } \\
\cline { 3 - 6 } Collection sites & No. analysed (HBI,\%) & Human N (\%) & Bovine N (\%) & Mixed N (\%) & Unknown N (\%) \\
\hline Indoor CDC light traps & $988(75)$ & $94(9.5)$ & $70(7)$ & $644(65)$ & $180(18)$ \\
Space sprays catches & $352(38)$ & $59(17)$ & $154(44)$ & $74(21)$ & $65(18.5)$ \\
Outdoor pit shelters & $894(13)$ & $27(3)$ & $521(58)$ & $89(10)$ & $257(29)$ \\
$\quad$ Total & $2234(44)^{*}$ & $180(8)$ & $745(33)$ & $807(36)$ & $502(22.5)$ \\
\hline
\end{tabular}

Mixed (human + bovine) blood meals were added to the number of human and bovine blood meals when calculating the HBI; numbers in parenthesis. Unknown blood meals are negative for human and bovine antibodies. * Overall HBI of An. arabiensis. 


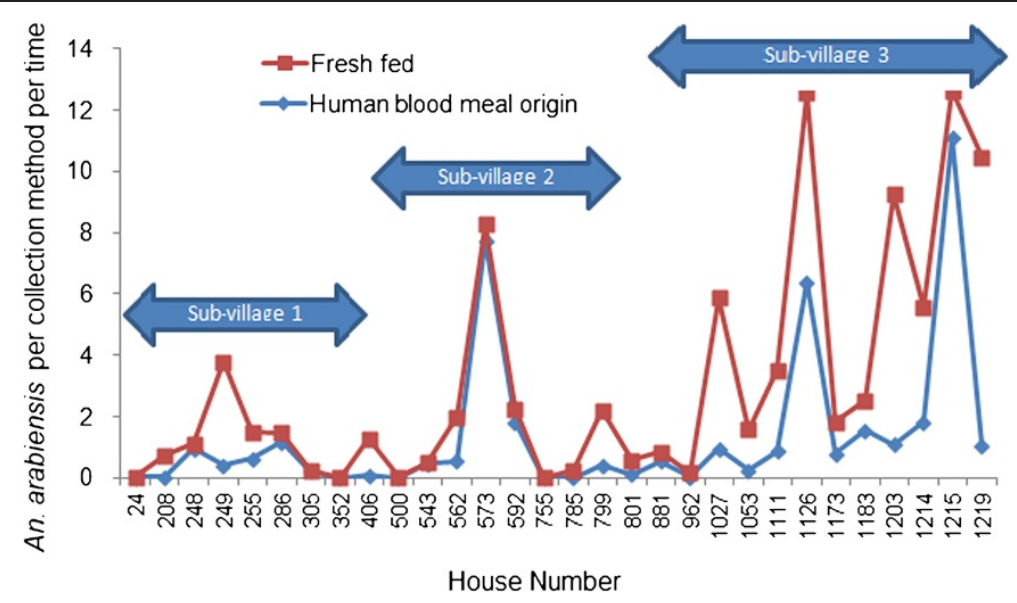

Figure 1 Variation of fresh fed and human blood fed An. arabiensis among the three sub-villages from Chano in southwest Ethiopia. (Pyrethrum spray catches: 24, 255, 352, 543, 785, 801, 962, 1111, 1183 \& 1214; CDC light traps: 248, 286, 305, 573, 592, 755, 881, 1126, 1173 \& 1215; Pit shelter: 208, 249, 406, 500, 562, 799, 1027, 1053, 1203 \& 1219).

The mortality rates of An. arabiensis after the 24-hour recovery period was $56 \%$ for lambdacyhalothrin, $50 \%$ for cyfluthrin and alphacypermethrin, $47 \%$ for deltamethrin and only $10 \%$ for DDT, much lower than the susceptibility boundary of $80 \%$ (Table 4 ). The mortality rate calculated for the experimental tests was not corrected because mortality in the controls was always less than $5 \%$.

\section{Discussion}

The results of this study showed that Anopheles arabiensis is the predominant anopheline species in the area, and it feeds mainly on cattle. An. arabiensis has already developed resistance to the available pyrethroid insecticides and alternative insecticides may be needed for the treatment of cattle. Houses close to the main mosquito breeding site harboured more freshly fed $A n$. Arabiensis and those fed on human blood.

Earlier studies from Ethiopia have examined the blood meal origins of An. arabiensis from animal sheds and human dwellings during the main malaria transmission seasons only $[3,5,6]$, neglecting the dry months. A strength of our study is that the blood meal origins of freshly fed An. arabiensis were determined by collecting mosquitoes from outdoor pit shelters and inside houses throughout a year, as was recommended by GarrettJones [7]. Mosquitoes were sampled from 30 collection sites every two weeks each month and, hence, their blood meals are representative of human contact with the mosquito vector. Our data compare well with those of Loha and Lindtjørn [20], who studied the incidence of malaria in the same village and reported the highest incidence of malaria in the nearest village to Lake Abaya (sub-village 3), where we found the highest densities of freshly fed and human-fed An. arabiensis.

One limitation of our study was the inability to determine the cryptic mixed blood meals of malaria vectors that had fed on different individuals of the same species. This might have led to underestimation of human-vector contact and pathogen transmission intensity, as was reported by Norris et al. [29] and Scott and Takken [1].

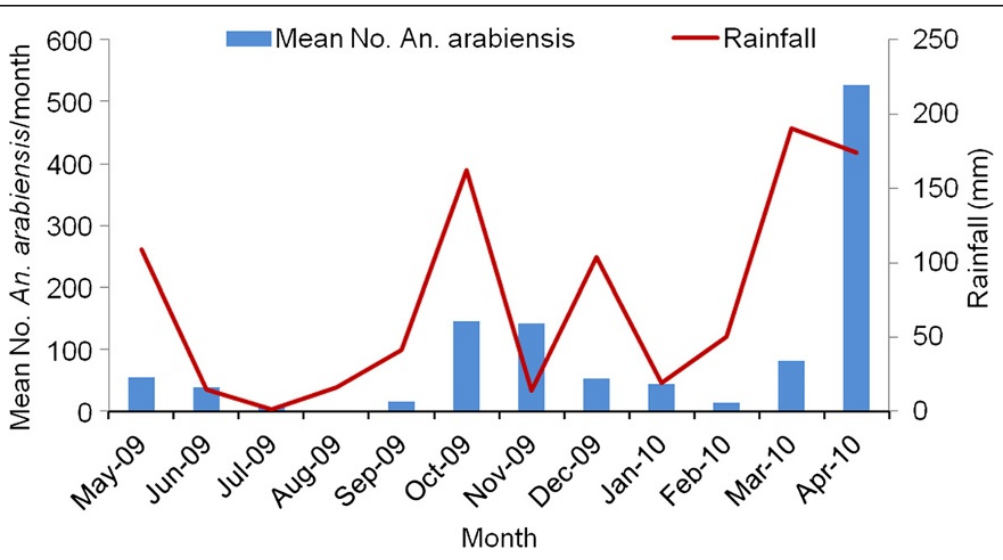

Figure 2 Monthly rainfall (in $\mathrm{mm}$ ) and the mean density of fresh fed Anopheles arabiensis from Chano in southwest Ethiopia. 


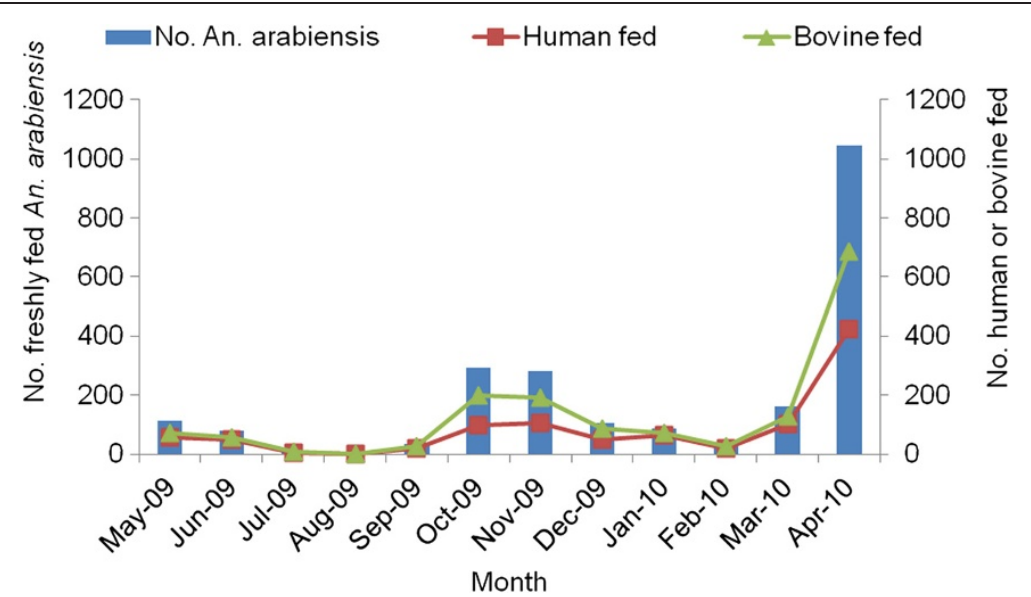

Figure 3 Number of freshly fed, human and bovine blood fed (mixed blood meal included in both human and bovine) Anopheles arabiensis from Chano in southwest Ethiopia.

Another limitation is that we could not identify other animal sources of blood meals for malaria vectors in addition to humans and cattle. Such information may be important in the planning of vector control options. The failure to determine the blood meal origins of some freshly fed $A n$. arabiensis may have occurred because we lacked antibodies for other hosts, or it could have resulted from enzymatic degradation of the blood.

Many zoophilic An. arabiensis were collected indoors using space spray catches after they had fed on cattle outdoors, which provides clear evidence for preference of a bovine blood meal over human. The zoophilic behaviour of An. arabiensis observed in this study is consistent with other findings from Ethiopia [3,6]. The HBI (38\%) of An. arabiensis from space spray catches was lower than the HBI from southern Zambia (92.3\%) [30], the Kenyan coast (91\%) [31], Konso in southern Ethiopia (55.2\%) [3] and the Gambia (82\%) [32], but higher than from Eritrea (20\%) [33] and western Kenya (23\%) [13]. The percentage of mixed blood meals for indoor resting An. arabiensis (21.0\%) was comparable with that found in other studies [13,34]. No mixed blood meals were identified in resting An. arabiensis from inside houses in Kenya [31].

The An. arabiensis collected using CDC light traps had higher HBI than those from indoor resting and outdoor pit shelters. Fornadel et al. [35] reported an HBI of $94 \%$ for An. arabiensis from southern Zambia collected using CDC light traps. Interestingly, a high proportion of $A n$. arabiensis from indoor CDC light traps had mixed blood meals (65.2\%). This suggests that they were interrupted while feeding outdoors on cattle and moved into houses to complete their feeding in a single night or on consecutive nights $[29,36]$. The lowest HBI was found for An. arabiensis from pit shelters located near cattle that are kept outdoors. This reveals that the accessibility of hosts influences the feeding behaviour of this species, as also reported by others [37]. This is the first report of the HBI of $A n$. marshalli and An. garnhami. Future studies should be conducted to examine the sporozoite rate of these species to determine their possible role in malaria transmission.

The few An. funestus collected from outdoor pit shelters was found with cattle blood meal. Unfortunately, we did not identify the species group using molecular method. However, the occurrence of some species from larval identification is known in Ethiopia [38]. Of the members of the group, An. parensis and An. rivulorum are regarded to be zoophilic elsewhere in Africa $[39,40]$. An. funestus has been incriminated as an anthropophilic and endophilic malaria vector in many

Table 4 Percent knockdown, knockdown time (KDT) (in minutes) and mortality rates of Anopheles arabiensis exposed to pyrethroids and DDT from Chano in Southwest Ethiopia

\begin{tabular}{|c|c|c|c|c|c|c|}
\hline Insecticides tested & Number exposed & \% knockdown & $\mathrm{KDT}_{50}(95 \% \mathrm{Cl})$ & $\mathrm{KDT}_{90}(95 \% \mathrm{Cl})$ & $\%$ mortality $( \pm \mathrm{SE})$ & Status [27] $(<80 \%)$ \\
\hline Lambdacyhalothrin (0.05\%) & 80 & 80 & $39(36-43)$ & ** & $56 \pm 9.6$ & resistant \\
\hline Alphacypermethrin (0.05\%) & 80 & 89 & $27(20-32)$ & ** & $50 \pm 5.4$ & resistant \\
\hline Cyfluthrin $(0.15 \%)$ & 80 & 96 & $25(19-29)$ & $42(37-51)$ & $50 \pm 9.5$ & resistant \\
\hline Deltamethrin (0.05\%) & 80 & 100 & $21(18-23)$ & $35(31-39)$ & $47 \pm 3.2$ & resistant \\
\hline DDT (4\%) & 80 & 10 & * & $* *$ & $10 \pm 3.5$ & resistant \\
\hline
\end{tabular}

* 50\% was not knocked down ** 90\% was not knocked down, $\mathrm{Cl}=$ confidence interval, $\mathrm{SE}=$ standard error. 
countries in Africa [41]. Therefore, the An. funestus group identified morphologically in this study could be either An. rivulorum or An. parensis or both .

In this study area, the distribution of the malaria vector was seasonal. The maximum number of freshly fed and human blood meal-engorged An. arabiensis was recorded one month after the peak rainfall. Possible reasons are that the rainfall in the previous month may have provided more breeding sites and increased the relative humidity, which contributes to a high density and longevity of the vectors and consequently increases human-vector contact [42]. In particular, the longevity of the vector is crucial for disease transmission because it increases the chance of an infectious bite occurring [42]. Kristan et al. [43] have also shown a one month lag after rainfall as a predictor of vector density in the African highlands. A study from Eritrea also has shown an increase in the An. arabiensis population one month after the start of rainfall [33]. Moreover, the distribution of $A n$. arabiensis was influenced mainly by the location of breeding sites on the shore of Lake Abaya. A study from the same area [20] and one from Northern Tanzania [44] showed a higher risk of malaria infection in a population living near to mosquito breeding sites. To locate and identify households at greater risk of malaria is, therefore, crucial in the planning and implementation of vector control approaches.

An. arabiensis showed a high level of resistance to knockdown and mortality in response to pyrethroid insecticides (deltamethrin, alphacypermethrin, lambdacyhalothrin and cyfluthrin) and DDT. The knockdown resistance was most likely due to the possession of various detoxifying enzymes. Studies from East and Central Africa $[45,46]$ have reported the occurrence of high levels of mono-oxygenase enzymes in resistant An. arabiensis. Elevated levels of mixed function oxidases and $\beta$-esterases were also reported in resistant An. arabiensis in Tanzania [47]. Moreover, the West African $k d r$ mutation (L1014F) detected in high frequencies in South-West and Northern Ethiopian An. arabiensis populations [18,48] could be another reason for high knockdown resistance in the study area. The $\mathrm{KDT}_{50}$ of lambdacyhalothrin (39 minutes) was higher than that of the other pyrethroid insecticides, but shorter than that reported from Senegal (43.6 minutes) in An. gambiae [49]. Compared with studies from Ethiopia, the $\mathrm{KDT}_{50}$ values of 25.3 minutes for An. arabiensis from Gorgora and 37.6 minutes from Ghibe were higher than that we observed for deltamethrin (21 minutes), but similar to that reported from Sodere (21.9 minutes) [18]. The impact of knockdown resistance is that it can allow the vectors to bite humans even inside the long lasting insecticide treated nets (LLINs) because the vector can withstand a long duration of exposure without being knocked down [50].
The high level of resistance of An. arabiensis to deltamethrin and DDT is not surprising because of the long history of the use of DDT for IRS and the widespread use of deltamethrin for LLINs and IRS, and cross-resistance may occur [51]. The high level of DDT (90\%) resistance in An. arabiensis was expected because $60 \%$ resistance was reported from South-Western Ethiopia 14 years ago [19]. The mortality rate $(10 \%)$ due to DDT was slightly higher than that reported by Yewhalaw and his colleagues $[17,48]$ but lower than that observed by Balkew et al. [18,52]. The mortality rate due to deltamethrin (47\%) was lower than that observed in other studies in Ethiopia $[17,18,48]$.

The resistance of An. arabiensis to alphacypermethrin, lambdacyhalothrin and cyfluthrin was unexpected because they have not been used for vector control. This implies that the use of insecticides with similar modes of action could shorten the duration of efficacy of other insecticides of the same class once resistance has developed in the mosquito population [53]. The most likely explanation is the presence of cross-resistance between insecticides of the same group [51], which might limit the choice of alternative insecticides for vector control. Cross-resistance between DDT and permethrin has been reported in Ethiopia [18] in An. arabiensis. No information is available in Ethiopia about the resistance of An. arabiensis to alphacypermethrin, lambdacyhalothrin and cyfluthrin. A study from Ghana has shown high survival rates of An. gambiae s.s after exposure to cyfluthrin and lambdacyhalothrin [54].

The results obtained in this study have implications for vector control. An. arabiensis showed a tendency to feed more frequently on cattle than on humans. In similar settings, Mahande and colleagues [16] and Rowland et al. [15] reported the success of treatment of cattle with pyrethroid insecticides in controlling zoophilic malaria vectors. Moreover, the preference of $A n$. arabiensis to rest indoors after feeding on cattle outdoors in an area that practises indoor-based vector control activities could explain the low efficacy of LLINs and IRS, owing to the resistance of $A n$. arabiensis to pyrethroid insecticides. Previously, N'Guessan et al. [55] reported a low efficacy of LLINs and IRS in areas with resistant malaria vectors. On the other hand, the indoor resting preference of $A n$. arabiensis is an opportunity to use current indoor based antivector strategies [56] because mosquitoes inside houses are easily targeted [57], but appropriate management of insecticide resistance needs to be implemented.

The possible explanation for the higher HBI and presence of mixed blood meals in An. arabiensis from indoor CDC light traps may be that most people are bitten indoors before they go to bed, or that protection from indoor antivector interventions is reduced by the presence of pyrethroid-resistant An. arabiensis. In the same setting, 
Loha and Lindtjørn [20] described the personal protection role of LLINs, with no impact on community members who did not use the nets. It is the killing capacity that provides protection from the infectious bites of malaria vectors for people in the community who do not use bed nets [58]. In an area with pyrethroid-resistant malaria vectors, even the combination of LLINs and IRS has a low impact on the prevalence of malaria [59], and in other settings an increase in malaria cases has been reported [60]. Asidi et al. [61] showed that the treatment of bed nets with pyrethroid insecticides provides additional protection from mosquito bites only if the vectors are susceptible to the chemicals. Our findings also show that the density of freshly fed and human blood-fed An. arabiensis increased in April 2010 despite the mass distribution of bed nets in March 2010. Hence, it is advisable to introduce additional vector control strategies that target a reduction in the entry of blood-searching vectors into houses and diversion to alternative hosts available outdoors. However, we should not underestimate the fact that malaria transmission can occur outdoors via humanbiting mosquitoes, even if the HBI is low [62].

In addition, the finding of the lowest HBI and percentage of mixed blood meals in An. arabiensis from outdoor pit shelters suggests that An. arabiensis is less likely to leave houses after feeding indoors on humans [13], or that people are bitten outdoors less frequently in the area. Therefore, IRS and LLINs can provide successful protection from malaria infection if the vectors are susceptible to the available pyrethroid insecticides.

\section{Conclusion}

Although a high propensity for An. arabiensis to feed on bovine blood was observed in our study area, treatment of cattle with insecticides may not reduce the vector density because An. arabiensis has already developed resistance to the available pyrethroid insecticides that are recommended for the treatment of cattle. Thus, alternative insecticides with different modes of action may be needed for treatment of cattle.

\section{Competing interests}

The authors have no conflict of interest.

\section{Authors' contributions}

FM: Project design, conducted field and laboratory work, data analysis and interpretation, wrote the draft of manuscript, MB: Project design, field and laboratory supervision, and manuscript revision, TG: Project design, supervision and manuscript revision, BL: Project design, field supervision, provided statistical input and manuscript revision. All authors read and approved the final manuscript.

\section{Acknowledgments}

Centre for International Health, University of Bergen in Norway provided the financial support. We thank Aklilu Lemma Institute of Pathobiology for allowing us to use their laboratory and give technical support. The authors also thank Arba Minch University for providing transport for field work. We thank the laboratory technicians in Aklilu Lemma Institute of Pathobiology and the field assistants in Chano for their contributions. Finally, the authors would like to appreciate the residence of Chano for their participation and allowing us to collect mosquitoes.

\section{Author details}

${ }^{1}$ Department of Biology, Arba Minch University, Arba Minch, Ethiopia. ${ }^{2}$ Aklilu Lemma Institute of Pathobiology, Addis Ababa University, Addis Ababa, Ethiopia. ${ }^{3}$ Centre for International Health, University of Bergen, Bergen, Norway.

Received: 30 August 2012 Accepted: 19 February 2013

Published: 22 February 2013

\section{References}

1. Scott T, Takken W: Feeding strategies of anthropophilic mosquitoes result in increased risk of pathogen transmision. Trends Parasitol 2012, 28:114-121.

2. Mahande A, Mosha F, Mahande J, Kweka E: Feeding and resting behaviour of malaria vector. Anopheles arabiensis with reference to Zooprophylaxis. Malar J 2007, 6:100.

3. Habtewold T, Walker AR, Curtis CF, Osir EO, Thapa N: The feeding behaviour and Plasmodium infection of Anopheles mosquitoes in southern Ethiopia in relation to use of insecticide -treated livestock for malaria control. Trans R Soc Trop Med Hyg 2001, 95:584-586.

4. Hadis M, Lulu M, Makonnen Y, Asfaw NT: Host choice by indoor-resting Anopheles arabiensis in Ethiopia. Trans R Soc Trop Med Hyg 1997, 91:376-378.

5. Adugna N, Petros B: Determination of the human blood index of some anopheline mosquitos by using ELISA. Ethiop Med J 1996, 34:1-10.

6. Tirados ICC, Gibson G, Torr SJ: Blood feeding behaviour of the malaria mosquito Anopheles arabiensis: implications for vector control. Med Vet Entomol 2006, 20:425-437.

7. Garrett-Jones C: The human blood index of malaria vectors in relation to epidemiological assessment. Bull World Health Organ 1964, 30:241-261.

8. Zaim M, Aitio A, Nakashima N: Safety of pyrethroid-treated mosquito nets. Med Vet Entomol 2000, 14:1-5.

9. Kleinschmidt I, Schwabe C, Benavente L, Torrez M, Ridl FC, Segura JL, Ehmer $P$, Nchama GN: Marked Increase in child survival after four years of intensive malaria control. AmJTrop Med Hyg 2009, 80:882-888.

10. Lengeler $C:$ Insecticide-treated bed nets and curtains for preventing malaria. Cochrane Database Syst Rev 2004, 2:CD000363.

11. Takken W: Do insecticide-treated bednets have an effect on malaria vectors? Trop Med Int Health 2002, 7:1022-1030.

12. Bogh C, Pedersen EM, Mukoko DA, Ouma JH: Permethrin-impregnated bednet effects on resting and feeding behaviour of lymphatic filariasis vector mosquitoes in Kenya. Med Vet Entomol 1998, 12:52-59.

13. Githeko A, Service MW, Mbogo CM, Atieli FK, Juma FO: Origin of blood meals in indoor and outdoor resting malaria vectors in western Kenya. Acta Trop 1994, 58:307-316

14. Pappa V, Reddy M, Overgaard HJ, Abaga S, Caccone A: Estimation of the human blood index in malaria mosquito vectors in Equatorial Guinea after indoor antivectorial interventions. AmJTrop Med Hyg 2011, 84:298-301.

15. Rowland M, Durrani N, Kenward M, Mohammed N, Urahman H, Hewitt S: Control of malaria in Pakistan by applying deltamethrin insecticide to cattle: a community - randomized trail. Lancet 2001, 357:1837-1841.

16. Mahande A, Mosha FW, Mahande JM, Kweka EJ: Role of cattle treated with deltamethrine in areas with a high population of Anopheles arabiensis in Moshi, Northern Tanzania. Malar J 2007, 6:109.

17. Yewhalaw D, Wassie F, Steurbaut W, Spanoghe P, Van Bortel W, Denis L, Tessema DA, Getachew Y, Coosemans M, Duchateau L, Speybroeck N: Multiple insecticide resistance: an impediment to insecticide-based malaria vector control program. PLoS One 2011, 6:e16066.

18. Balkew M, Ibrahim M, Koekemoer LL, Brooke BD, Engers H, Aseffa A, GebreMichael T, Elhassen I: Insecticide resistance in Anopheles arabiensis (Diptera: Culicidae) from villages in central, northern and south west Ethiopia and detection of kdr mutation. Parasit Vectors 2010, 3:40.

19. Abose T, Yeebiyo Y, Olana D, Alamirew D, Beyene Y, Regassa L, Mengesha A: Re-orientation and Definition of the Role of Malaria Vector Control in Ethiopia. Malaria Prevention and Control programme. Geneva: World Health Organization Division of Control of Tropical Diseases; 1998.

20. Loha E, Lindtjorn B: Predictors of plasmodium falciparum malaria incidence in Chano Mille, South Ethiopia: a longitudinal study. AmJTrop Med Hyg 2012, 87:450-459. 
21. WHO: Manual on practical entomology in malaria part 2: methods and techniques. Geneva: World Health Organization; 1975.

22. WHO: Malaria entomology and vector control. Geneva: World Health Organization HIV/AIDS, Tuberculosis and Malaria; 2003.

23. Silver J: Mosquito ecology: field sampling methods. 3rd edition.: Springer; 2008.

24. Gillies M, Coetzee M: A supplement to the anopheline of Africa South of Sahara. S Afr Inst Med Res 1987, 55:143.

25. Beier J, Perkkins PV, Wirtz RA, Koros J, Diggs D, Gargan TP, Koech DK: Bloodmeal identification by direct-enzyme linked immunosorbent assay (ELISA), tested on Anopheles (Diptera: Culicidae) in Kenya. J Med Entomol 1988, 25:9-16

26. Scott J, Brogdon WG, Collins FH: Identification of single specimens of the Anopheles gambiae complex by the polymerase chain reaction. AmJTrop Med Hyg 1993, 49:520-529.

27. WHO: Test procedures for insecticide resistance in malaria vectors, bio-efficacy and persistence of insecticides on treated surfaces. Geneva: World Health Organization; 1998.

28. Mala A, Irungu LW, Shililu Jl, Muturi EJ, Mbogo CM, Njagi JK, Mukabana WR, Githure Jl: Plasmodium falciparum transmission and aridity: a Kenyan experience from the dry lands of Baringo and its implications for Anopheles arabiensis control. Malar J 2011, 10:121

29. Norris L, Fornadel CM, Hung WC, Pineda FJ, Norris DE: Frequency of multiple blood meals taken in a single gonotrophic cycle by Anopheles arabiensis mosquitoes in Macha, Zambia. AmJTrop Med Hyg 2010, 83:33-37.

30. Kent R, Thuma PE, Mharakurwa S, Norris D: Seasonality, blood feeding behaviour, and transmission of Plasmodium falciparum by anopheles arabiensis after an extended drought in southern Zambia. AmJTrop Med Hyg 2007, 76:267-274.

31. Mwangangi J, Mbogo CM, Nzovu JG, Githure JI, YAN G, Beier JC: Bloodmeal analysis for anopheline mosquitoes sampled along the Kenyan coast. J Am Mosq Control Assoc 2003, 19:371-375.

32. Bøgh C, Clarke SE, Pinder M, Sanyang F, Lindsay SW: Effect of passive zooprophylaxis on malaria transmission in The Gambia. J Med Entomol 2001, 38:822-828.

33. Waka M, Hopkins RJ, Akinpelu O, Curtis C: Transmission of malaria in the Tesseney area of Eritrea: parasite prevalece in children, and vector density, host preferences, and sporozoite rate. J Vector Ecol 2005, 30:27-31.

34. Fontenille D, Lochouarn L, Diatta M, Sokhna C, Dia I, Diagne N, Lemasson JJ, Ba K, Tall A, Rogier C, Trape JF: Four years' entomological study of the transmission of seasonal malaria in Senegal and the bionomics of Anopheles gambiae and An. arabiensis. Trans R Soc Trop Med Hyg 1997, 91:647-652

35. Fornadel C, Norris LC, Glass GE, Norris DE: Analysis of Anopheles arabiensis blood feeding behavior in Southern Zambiaduring the TwoYears after introduction of insecticide-treated BedNets. Am JTrop Med Hyg 2010, 83:848-853.

36. Lemasson J, Fontenille D, Lochouarn L, Dia I, Simard F, Ba K, Diop A, Diatta M, Molez JF: Comparison of behavior and vector efficiency of Anopheles gambiae and An. arabiensis (Diptera:Culicidae) in Barkedji, a Sahelian area of Senegal. J Med Entomol 1997, 34:396-403.

37. Killeen G, McKenzie FE, Foy BD, Bøgh C, Beier JC: The availability of potential hosts as a determinant of feeding behaviours and malaria transmission by African mosquito populations. Trans $R$ Soc Trop Med Hyg 2001, 95:469-476.

38. Gebre-Mariam N: The Ecology of Health and Disease in Ethiopia. In Malaria. Edited by Zein AZ, Kloos H. Addis Ababa: Ministry of Health; 1988:136-150.

39. Mouatcho J, Hargreaves K, Koekemoer LL, Brooke BD, Oliver SV, Hunt RH, Coetzee M: Indoor collections of the Anopheles funestus group (Diptera: Culicidae) in sprayed houses in northern KwaZulu-Natal, South Africa. Malar J 2007, 6:30

40. Kawada H, Dida GO, Sonye G, Njenga SM, Mwandawiro C, Minakawa N: Reconsideration of Anopheles rivulorum as a vector of Plasmodium falciparum in Western Kenya: some evidence from biting time, blood preference, sporozoite positive rate, and pyrethroid resistance. Parasit Vectors 2012, 5:230.

41. Coetzee M, Fontenille D: Advances in the study of Anopheles funestus, a major vector of malaria in Africa. Insect Biochem Mol Biol 2004, 34:599-605.

42. Protopopoff N, Bortel WW, Speybroeck N, Geertruyden JPV, Baza D, D'Alessandro U, Coosemans M: Ranking malaria risk factors to guide malaria control efforts in African highlands. PLoS One 2009, 4:e8022.

43. Kristan M, Abeku TA, Beard J, Okia M, Rapuoda B, Sang J, Cox J: Variations in entomological indices in relation to weather patterns and malaria incidence in East African highlands: implications for epidemic prevention and control. Malar J 2008, 7:231.

44. Oesterholt M, Bousema JT, Mwerinde OK, Harris C, Lushino P, Masokoto A, Mwerinde $\mathrm{H}$, Mosha FW, Drakeley CJ: Spatial and temporal variation in malaria transmission in a low endemicity area in northern Tanzania. Malar J 2006, 5:98.

45. Vulule JM, Beach RF, Atieli FK, MCAllister JC, Brogdon WG, Roberts JM, Mwangi RW, Hawley WA: Elevated oxidase and esterase levels associated with permethrin tolerance in Anopheles gambiae from Kenyan villages using permethrin-impregnated nets. Med Vet Entomol 1999, 13:239-244.

46. Etang J, Manga L, Toto JC, Guillet P, Fondjo E, Chandre F: Spectrum of metabolic-based resistance to DDT and pyrethroids in Anopheles gambiae s.l. populations from Cameroon. J Vec Ecol 2007, 32:123-133.

47. Matowo J, Kulkarni MA, Mosha FW, Oxborough RM, Kitau JA, Tenu F, Rowland M: Biochemical basis of permethrin resistance in Anopheles arabiensis from Lower Moshi, north-eastern Tnazania. Malar J 2010, 9:193.

48. Yewhalaw D, Bortel W, Denis L, Coosemans M, Duchateau L, Speybroeck N First evidence of high knockdown resistance frequency in Anopheles arabiensis (Diptera: Culicidae) from Ethiopia. AmJTrop Med Hyg 2010, 83:122-125.

49. Ndiath MO SS, Gaye A, Mazenot C, Konate L, Faye O, Sokhna C, Trape JF: Resistance to DDT and pyrethroids and increased kdr mutation frequency in An. gambiae after the implementation of permethrintreated nets in Senegal. PLoS One 2012, 7:e3194.

50. Ranson H, N'Guessan R, Lines J, Moiroux N, Nkuni Z, Corbel V: Pyrethroid resistance in African anopheline mosquitoes: what are the implications for malaria control? Trends Parasitol 2011, 27:91-98.

51. Nauen $\mathrm{R}$ : Insecticide resistance in disease vectors of public health importance. Pest Manag Sci 2007, 63:628-633.

52. Balkew M, Gebre-Michael T, Hailu A: Insecticide susceptibility level of Anopheles arabiensis in two agrodevelopment localities in Eastern Ethiopia. Parassitologia 2003, 45:1-3.

53. WHO: Global plan for insecticide resistance managment in malaria vectors (GPIRM). Geneva: World Health Organization global malaria programme; 2012

54. Coetzee $M$, van Wyk P, Booman M, Koekemoer LL, Hunt RH: Insecticide resistance in malaria vector mosquitoes in a gold mining town in Ghana and implications for malaria control. Bull Soc Pathol Exot 2006, 99:400-403.

55. N'Guessan R, Corbel V, Akogbéto M, Rowland M: Reduced efficacy of insecticide-treated nets and indoor residual spraying for malaria control in pyrethroid resistance area, Benin. Emerg Infect Dis 2007, 13:199-206.

56. Fornadel C, Norris DE: Increased endophily by the malaria vector Anopheles arabiensis in Southern Zambia and identification of digested blood meals. AmJTrop Med Hyg 2008, 79:876-880.

57. Davidson G: Experiments on the effect of residual insecticides in houses against Anopheles gambiae and A. funestus. Bull Entomol Research 1953, 44:231-254.

58. Gu W, Novak RJ: Predicting the impact of insecticide-treated bed nets on malaria transmission: the devil is in the detail. Malar J 2009, 8:256.

59. Corbel V, Akogbeto M, Damien GB, Djenontin A, Chandre F, Rogier C, Moiroux N, Chabi J, Banganna B, Padonou GG, Henry MC: Combination of malaria vector control interventions in pyrethroid resistance area in Benin: a cluster randomised controlled trial. Lancet Infect Dis 2012, 3099:70081-70086

60. Trape J, Tall A, Diagne N, Ndiath O, Ly AB, Faye J, Dieye-Ba F, Rou cher C, Bouganali C, Badiane A, Diene Sarr F, Mazenot C, Touré-Baldé A, Raoult D, Druilhe P, Mercereau-Puijalon O, Rogier C, Sokhna C: Malaria morbidity and pyrethroid resistance after the introduction of insecticide-treated bednets and artemisinin-based combination therapies: a longitudinal study. Lancet 2011, 3099:70194-70202.

61. Asidi A, N'Guessan R, Akogbeto M, Curtis C, Rowland M: Loss of household protection from use of insecticide-treated nets against pyrethroidresistant mosquitoes, Benin. Emerg Infect Dis 2012, 18:1101-1106.

62. Reddy M, Overgaard HJ, Abaga S, Reddy VP, Caccone A, Kiszewski AE, Slotman MA: Outdoor host seeking behaviour of Anopheles gambiae mosquitoes following initiation of malaria vector control on Bioko Island, Equatorial Guinea. Malar J 2011, 10:184

doi:10.1186/1756-3305-6-44

Cite this article as: Massebo et al:: Blood meal origins and insecticide susceptibility of Anopheles arabiensis from Chano in South-West Ethiopia. Parasites \& Vectors 2013 6:44 